\title{
Breves considerações sobre processos de apropriação de traços identitários brasileiros, em anúncios publicitários do Instituto Brasileiro de Turismo-Embratur ${ }^{1}$
}

\section{Resumo}

Patrícia de Souza Figueredo Lima Annamaria da Rocha Jatobá Palacios ${ }^{b}$

Este texto analisa aspectos da apropriação de traços identitários brasileiros, em campanha publicitária do Ministério do Turismo do Brasil, através da Embratur, voltada para públicos internacionais. As peças publicitárias foram produzidas com vistas a atrair turistas para a Copa do Mundo e Olimpíadas que tiveram lugar no Brasil, respectivamente em 2014 e 2016. A pesquisa realizada mostra que, com relação a campanhas anteriores, buscou-se representar uma maior diversidade de atrativos turísticos e traços identitários. Por meio da evocação a práticas culturais mundialmente conhecidas (a exemplo do futebol e da capoeira) e sua conjunção com outras menos difundidas (a exemplo do maracatu), a Embratur buscou destacar a diversidade cultural brasileira no processo de construção de sua imagem turística, para circulação em dimensão internacional. No entanto, é identificável a continuidade e persistência de uma visão tradicional, unificada e homogeneizante com respeito a traços da identidade brasileira, associados especialmente à alegria, hospitalidade e multietnicidade.

Palavras-chave: Identidades; Publicidade; Turismo; Imagem Turística; Análise do Discurso

\begin{abstract}
Some considerations on processes of appropriation of Brazilian identity traits, in advertisements produced by the Brazilian Institute of Tourism - Embratur

This text analyzes aspects of the appropriation of Brazilian identity traits in an advertising campaign produced by the Brazilian Ministry of Tourism (Embratur) and aimed at international audiences. Advertising pieces were produced with a view to attract tourists to the World Cup and Olympics that would take place in Brazil, respectively in 2014 and 2016. The research carried out shows that, in relation to previous campaigns, the representation of a greater diversity of tourist attractions and identity traits were sought. Through the evocation of world-known cultural practices (such as football and capoeira) and its conjunction with lesser-known ones (like maracatu), Embratur sought to highlight the Brazilian cultural diversity for circulation in an international dimension. However, the continuity and persistence of a traditional, unified and homogenizing view on traits of Brazilian identity, associated especially with joy, hospitality and multiethnicity, is identifiable.
\end{abstract}

Keywords: Identities; Publicity; Tourism; Tourist Image; Speech Analysis

1. Versão preliminar do referido texto foi apresentada no III Congresso Internacional sobre Culturas: Interfaces da Lusofonia, realizado na Universidade do Minho, cidade de Braga, Portugal, nos dias 23, 24 e 25 de novembro 2017.

a. Mestre em Cultura e Sociedade, Universidade Federal da Bahia, Salvador, Bahia, Brasil. E-mail: patriciasfigueiredolima@gmail.com

b. Pós-Doutorado no curso Ciências da Comunicação, Universidade da Beira Interior, Covilhã, Portugal. Docente do curso de Comunicação na Universidade Federal da Bahia, Salvador, Bahia, Brasil. E-mail: annajatobapalacios@gmail.com 


\section{Resumen}

Breves consideraciones sobre procesos de apropiación de rasgos identitarios brasileños, en anuncios publicitarios del Instituto Brasileño de Turismo-Embratur

Este texto analiza aspectos de la apropiación de rasgos identitarios brasileños, en una campaña publicitaria del Ministerio de Turismo de Brasil (Embratur), volcada a públicos internacionales. Las piezas publicitarias fueron producidas con vistas a atraer turistas para la Copa del Mundo y Olimpiadas que tendrían en Brasil, respectivamente en 2014 y 2016. La investigación realizada muestra que, con relación a campañas anteriores, se buscó representar una mayor diversidad de atractivos turísticos y rasgos identitarios. Por medio de la evocación a prácticas culturales mundialmente conocidas (a ejemplo del fútbol y de la capoeira) y su conjunción con otras menos difundidas (a ejemplo del maracatu), Embratur buscó poner de relieve la diversidad cultural brasileña en el proceso de construcción de su imagen turística para circulación en una dimensión internacional. Sin embargo, es identificable la continuidad y persistencia de una visión tradicional, unificada y homogeneizante sobre rasgos de la identidad brasileña, asociados especialmente a la alegría, la hospitalidad y la multi-etnicidad.

Palabras clave: Identidades; Publicidad; Turismo; Imagen Turística; Análisis del Discurso

\section{INTRODUÇÃo}

Partindo do pressuposto de que a cultura midiática e o discurso publicitário possuem um relevante papel na construção da imagem sociocultural de destinos turísticos, este texto apresenta a síntese de investigações desenvolvidas no Programa Multidisciplinar de Pós-Graduação em Cultura e Sociedade, no âmbito da linha de pesquisa sobre Cultura e identidade. 0 texto objetiva investigar como o Ministério do Turismo do Brasil, através da Embratur, realiza a incorporação de traços identitários brasileiros na construção da imagem turística do país veiculada em outros países, através de campanhas publicitárias voltadas para públicos internacionais.

A campanha que compõe o corpus central do trabalho, cujo slogan é "O mundo se encontra no Brasil. Venha celebrar a vida", foi elaborada a partir das orientações do "Plano de Marketing Turístico Internacional - Plano Aquarela 2020", instrumento norteador das ações promocionais da Embratur para a década em que o Brasil sediou os dois principais eventos esportivos mundiais: Copa do Mundo de Futebol, em 2014, e os Jogos Olímpicos e Paralímpicos, em 2016.

0 texto compõe-se de quatro partes: na primeira, introduzimos o assunto, com ênfase na intersecção entre comunicação turística e prática publicitária e suas influências no processo de difusão da imagem turística do Brasil, por meio da campanha "O mundo se encontra no Brasil. Venha celebrar a vida", produzida pela Embratur e voltada para públicos internacionais; na segunda, abordamos os processos de incorporação de traços identitários da nacionalidade brasileira pela comunicação turística; na terceira parte, apresentamos anúncios publicitários que fazem parte da referida campanha, com apreciação de tais peças, à luz do referencial teórico selecionado para tal fim; na quarta parte, as considerações finais. 


\section{IDENTIDADES E PUBLICIDADE TURÍSTICA}

Diversos teóricos (Hall, 1997; Vieira, 2009; Canclini, 2008) chamam atenção para o enfraquecimento da ideia de identidades nacionais unificadas. Outros assinalam que a concepção de identidades culturais foi inventada (Silva, 2012) e construída pelo Estado (Bauman, 2005). Em diálogo com os referidos autores, partimos do entendimento de que as identidades são dinâmicas, relacionais, variáveis, narradas e marcadas simbolicamente através de processos de representação, especialmente nos processos globalizados e de midiatização que marcam a contemporaneidade.

A comunicação turística surge no contexto de midiatização globalizada, como elemento chave na diferenciação dos destinos, através da utilização das expressões culturais e de características naturais dos lugares, como forma de distinção no mercado turístico mundial. Conforme defendem Gastal e Sales (2012, p. 22), "as marcas do lugar e, portanto, as identidades a ele vinculadas, são elementos importantes na construção de produtos turísticos". Conforme as autoras, a cultura torna-se um importante insumo para os produtos turísticos, em especial no que se refere a traços advindos das especificidades étnicas. As autoras defendem que as identidades sob a ótica do turismo estão cada vez mais dinâmicas, uma vez que quanto mais aumentam os deslocamentos turísticos, maiores são as trocas culturais.

Diante de mercados cada vez mais competitivos, White (2017) argumenta que os destinos turísticos precisam se diferenciar um dos outros, estabelecendo uma base convincente e legítima para adquirir a preferência do consumidor. Neste sentido, a autora argumenta que a promoção turística é normalmente a voz mais proeminente na marca de uma nação. Deste modo, pretendemos abordar neste texto, como discursos turísticos, especialmente aquele oriundo do Instituto Brasileiro de Turismo, contribuem para a essencialização e simplificação da diversidade e complexidade do tecido social brasileiro, a fim de desenhar e fortalecer representações identitárias nacionais mais relevantes do ponto de vista comercial, ou seja, as que mais atendem às expectativas do olhar do turista.

Por ser uma atividade complexa, dinâmica e que promove o intercâmbio entre pessoas de diferentes culturas e origens econômicas, sociais e políticas, o turismo exerce relevante influência sobre os núcleos receptores, tanto em relação aos aspectos ambientais como em relação à sua dinâmica social e cultural. E, diante da complexidade e especificidade do produto ofertado, a comunicação turística engloba diversos suportes e estratégicas para atingir e influenciar os diferentes tipos de turistas. Para Voisin (2004, p. 7), a comunicação turística "toca as imagens identitárias de um território, a memória coletiva e social de um povo", uma vez que as representações difundidas através dela trazem repercussões significativas sobre o olhar que as comunidades receptoras dirigem a si mesmas diante dos visitantes.

Salientamos que, nos dias atuais, face ao processo de midiatização da sociedade e, consequentemente, do maior acesso às informações a respeito das destinações turísticas, sobretudo após o estabelecimento da comunicação digital, o papel da publicidade turística está mais relacionado com a construção de mecanismos de atração e estímulo ao consumidor para a realização da atividade, bem como também voltado para a construção de diferenciação em relação a outros destinos e produtos turísticos. 
A publicidade turística, de acordo com Conceição (1998, p. 72), promove o processo de antecipação da experiência de consumo ao turista. 0 discurso promocional deve, segundo a autora, retratar aquilo que o turista irá encontrar, transformando a viagem potencial em algo que reflita "o universo, os gostos e as aspirações de quem deseja partir". Já para Tomazzoni (2006, p. 348), “o discurso da mídia pode ser, então, mais atrativo, mais sedutor e mais turístico do que o próprio atrativo que ele divulga".

Cada vez mais, as práticas de consumo na contemporaneidade, inclusive as concernentes às atividades turísticas, encontram-se voltadas para o que Pereira, Siciliano e Rocha (2015, p. 9) definem como sendo da ordem do "consumo de experiência": "o uso social, reforçado pelo sistema de classificação e de significação da sociedade, de bens (consumo), que sejam, em si mesmos, as práticas e as interações sociais nele envolvidas (experiência)". Diferentemente de uma corriqueira experiência de consumo, o "consumo de experiência" pressupõe, de acordo com esta acepção, que a experiência seja, em si, o próprio bem de consumo.

De acordo com os autores, a diferença entre o "consumo de experiência" e a "experiência do consumo" reside, principalmente, em que o "primeiro pressupõe a total imersão do indivíduo em um ambiente alusivo a uma memória anterior e ao deslocamento do significado de identidades, objetos, ambientes, dentre outros elementos constitutivos o mundo real" (Pereira, Siciliano, \& Rocha, 2015, p. 10). Já a "experiência de consumo", conforme os autores, integra "toda e qualquer compra cotidiana que inclui algum tipo de troca e, portanto, experiência" (p. 7).

Assim, são definidos alguns pressupostos para que uma prática de consumo possa ser considerada como consumo de experiência, dentre as quais a existência de um espaço físico ou virtual intencionalmente preparado e ritualizado para a vivência de emoções e impressões, referenciado por narrativa previamente conhecida e por um acordo tácito entre os indivíduos em relação aos aspectos lúdicos, mágicos ou imaginados que farão parte deste simulacro.

Na acepção de Jean Baudrillard (citado por Freitas, 2013, p. 1), o simulacro é "o segundo batismo das coisas, acrescentando que o primeiro é a representação". Segundo o teórico, o simulacro "distorce o real, confundindo-se com o mesmo, e o que entra em jogo é a significação do valor das coisas". Para Baudrillard (1981, p.20), a Disneylândia é "um modelo perfeito de todos os tipos de simulacros confundidos [enchevêtrés, no original em francês]".

Do mesmo modo, a comercialização das experiências envolve o redimensionamento de inúmeros produtos e serviços, para além da atividade turística, de modo a oferecer uma diversidade de sensações ao consumidor. Neste turno, a publicidade se retroalimenta, ao mesmo tempo que reforça práticas de consumo contemporâneas.

Diante desse contexto, compreendemos que, além de pretender antecipar e prometer a vivência de experiências, a publicidade turística tem o papel de criar uma imagem atraente, estimular e seduzir o potencial turista a conhecer um destino turístico específico. Entretanto, através da utilização de recursos visuais e simbólicos, esta forma de comunicação publicitária tende a confirmar e reativar estereótipos e formas de representação já massificadas em relação a lugares e territórios, geograficamente conformados, contribuindo, muitas vezes, para o fortalecimento de imaginários alusivos aos lugares que, não necessariamente, correspondem às práticas cotidianas de seus moradores. 
Lamo (1993), ao articular estereótipo nacional e imagens turísticas, compreende que aquele é formado por uma série de traços abstraídos de modo descontextualizado nos quais se destacam por seu contraste e singularidade, e ao mesmo tempo, por sua similaridade (o que é menos frequente). Portanto, as imagens têm a ver mais com sua relação com o outro, com o contraste em relação às expectativas do espectador, do que com o que são em si mesmas, já que as imagens, assim como os estereótipos, "se constroem através da comparação (frequentemente tácita, oculta, inconsciente) entre o que se vê e o que se espera ver" (Lamo, 1993, p. 13).

Em relação aos impactos simbólicos oriundos da atividade turística em uma comunidade receptora, Pazos-Justo (2017, p. 83) considera relevante assinalar a imagem, compreendida enquanto discurso de representação, como fator principal a ter em consideração. Para o autor, a natureza das imagens em jogo no encontro entre visitantes e locais tem "uma relevância assinalável em duas direções: (i) quanto à representação que funciona efetivamente entre os visitantes e (ii) relativamente ao impacto que o fenómeno turístico pode exercer na autoimagem da comunidade receptora". Assim, fazendo referência a Lamo, na compreensão de que as imagens têm um caráter profético, o autor compreende que a tendência é a de ver e crer em relação à imagem prévia; assim, as imagens não só condicionam a eleição dos destinos, como também orientam as experiências, as atitudes, as práticas, ou seja, o próprio consumo (Pazos-Justo, 2017).

Nesta mesma linha, Tomazzoni (2006, p. 349), defende que:

o turista não "consome" o atrativo cultural ou ambiental, apenas o aprecia, admirando seus atributos, qualidades, peculiaridades e belezas, persuadido e envolvido pelas descrições e explicações que lhe são apresentadas. 0 que se consome, portanto, é o discurso que permeia as expectativas que habitam o imaginário, de satisfação de curiosidades e de necessidades de conhecer e de vivenciar ambientes culturais diferenciados.

Deste modo, veremos na próxima seção como a publicidade institucional, promovida pela Embratur, especialmente na campanha supramencionada, tem estimulado o conhecimento e a realização da visita de estrangeiros ao Brasil, por meio da evocação de traços identitários alusivos ao país.

\section{"O MUNDO SE ENCONTRA NO BRASIL. VENHA CELEbRAR A VIDA"}

A partir da elaboração do Plano de Marketing Turístico Internacional do Brasil, o Plano Aquarela 2020, é divulgada uma campanha publicitária direcionada especificamente para o público internacional intitulada "O mundo se encontra no Brasil. Venha celebrar a vida", lançada na abertura das Olimpíadas de 2012, em Londres. "O mundo se encontra no Brasil", segundo a Embratur, refere-se à história de miscigenação do país e aos encontros promovidos pelos grandes eventos internacionais, como a Copa do Mundo e as Olimpíadas. "Venha celebrar a vida" convida pessoas de todo o mundo a vivenciar experiências inesquecíveis no país (Instituto Brasileiro de Turismo, 2012b).

2. Trecho original, em espanhol: "se construyen a través a la comparación (frecuentemente tacita, oculta, inconsciente) entre lo que se ve y lo que se espera ver". 
O objetivo da campanha, de acordo com a Embratur, é realçar a riqueza cultural como um diferencial do Brasil. A campanha pretende ressaltar que, além da variedade de destinos, o país oferece uma rica gastronomia, manifestações artísticas e grandes festivais culturais em todas as regiões. A ideia é mostrar estes pilares que, somados ao traço histórico-cultural de simpatia atribuído ao povo brasileiro, proporcionariam experiências aos turistas que somente são possíveis de ser vivenciadas no Brasil (Instituto Brasileiro de Turismo, 2012b).

A campanha tem como mercados prioritários países da América Latina, tais como Argentina, Chile, Peru, Uruguai, Colômbia, Paraguai, Bolívia e México, além de Estados Unidos, Canadá, Inglaterra, Alemanha, França, Itália, Espanha, Portugal e Holanda. 0 público alvo prioritário, de acordo com a Embratur, é de pessoas com alto poder aquisitivo, com idade entre 25 e 55 anos.

A internet é o principal veículo utilizado para divulgação da campanha, por meio do qual foram lançados vídeos no Youtube, aplicativo em redes sociais, displays em sites, links patrocinados no Google, publicações nas redes sociais da Embratur (Twitter, Facebook e Youtube), dentre outros. Também foram veiculados anúncios em revistas e jornais impressos, comerciais em canais televisivos, mídia exterior, plotagem em táxis, ônibus e aeroportos, dentre outros.

Entendemos que uma campanha publicitária corresponde a um conjunto de peças que possuem uma identidade entre si e que foram concebidas através de objetivos estabelecidos, em geral, dentro de um plano de marketing. Garcia, Rocha Júnior e Sant'Anna (2009, p. 140) fazem uma analogia da campanha a um quebra-cabeça, "em que cada peça tem seu lugar, ocupa estrategicamente um espaço, conduz uma parte essencial da mensagem total". Ainda que a Embratur veicule uma campanha que pretende comercializar o Brasil enquanto destino turístico e, portanto, objetive divulgar um produto de natureza imaterial, sustentamos que esta acepção de campanha convencional, proposta pelos referidos autores aplica-se ao contexto pesquisado porque cada um dos anúncios, em conjunto com os suportes utilizados e seus modos de distribuição, constroem, através da interdiscursividade, uma mensagem conjunta e coerente, como veremos mais à frente.

Do mesmo modo, concordamos com a visão de Gastaldo (2013, p. 72) que considera um anúncio ou uma campanha publicitária, do ponto de vista mercadológico, como um elemento que compõe uma estratégia de marketing - "uma peça na complexa maquinaria mercadológica - que inclui redes de distribuição de produtos, posicionamento frente à concorrência, política de preços etc.". Segundo esse ponto de vista, a publicidade manipula elementos da cultura e os reapresenta sob a ótica de mercado e, por isso, constitui uma rica fonte de acesso a imaginários sociais. Tratando especificamente dos anúncios analisados e apresentados a seguir, objetivamos identificar quais aspectos relacionados às representações identitárias brasileiras, o governo (por meio da Embratur), julga mais adequados apresentar, considerando-se os mercados aos quais se destinam. Aqui, o interesse maior é perceber os principais traços alusivos a uma (única e suposta) identidade brasileira, moldada e delineada de modo a atrair o olhar e a visita do outro (o potencial turista estrangeiro).

Deste modo, pretendemos a partir da análise das peças publicitárias da campanha institucional já referida, destacar os dois pontos de vista do discurso publicitário: o que motiva a sua criação, produção e veiculação; e, ao mesmo tempo, os conteúdos simbólicos veiculados. 


\section{ANÚNCIOS}

Partimos do pressuposto que o anúncio é a materialização verbal e visual do discurso de uma campanha publicitária que, além de representar uma estratégia mercadológica, é uma janela que dá acesso, aos potenciais públicos consumidores, aos conteúdos simbólicos apropriados por ela. (Gastaldo, 2013). Os anúncios aqui analisados, veiculados em revistas e jornais dos mercados alvo, mostram personagens estrangeiros e brasileiros interagindo em diferentes destinos turísticos do país, ressaltando, de acordo com a Embratur (2012a) distintos aspectos da cultura brasileira.

Do total dos quinze anúncios que compõem a campanha e disponibilizados por e-mail pela Diretoria de Marketing da Embratur, optamos por apresentar uma análise, neste trabalho, de quatro deles, por fazerem referência mais clara a elementos da cultura e identidades brasileiras. Inicialmente, detalhamos a estrutura dos anúncios de modo a objetivar nossa análise, e perceber a intertextualidade presente, conforme os exemplos da Figura 1:

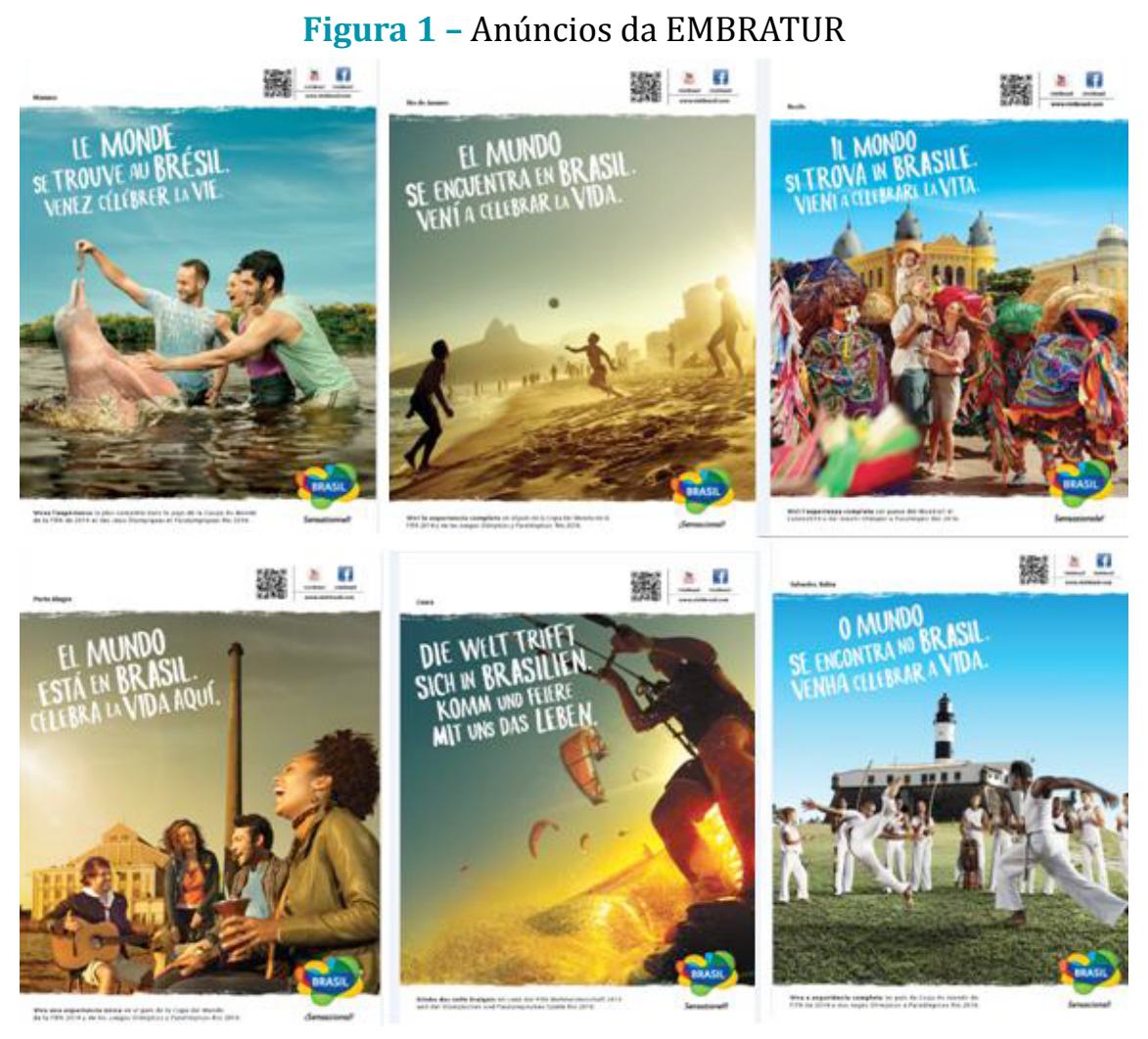

Fonte - Instituto Brasileiro de Turismo $(2014)^{3}$

- A imagem de um destino turístico brasileiro, sempre com a presença de personagens praticando alguma ação e/ou vivendo alguma experiência: conversando, realizando alguma atividade esportiva, rindo, interagindo entre si ou com algum elemento do ambiente, seja ele natural ou cultural;

3. Anúncios enviados por e-mail para uma das autoras pela Coordenação de Publicidade e Propaganda da Embratur, em abril de 2014. 
- A parte superior esquerda do anúncio identifica o local daquele cenário (Rio de Janeiro, Mato Grosso, Recife, Salvador, Manaus, dentre outros) e, à direita, há a presença de um Qr Code, da marca do canal Youtube e a identificação do site promocional da Embratur "/visitbrasil" e da marca do facebook e do endereço da fanpage "/visitbrasil";

- No centro do anúncio, em destaque, está o slogan "0 mundo se encontra no Brasil. Venha celebrar a vida", em português, ou em versões em diferentes idiomas (espanhol, francês, italiano, alemão, inglês e holandês);

- Na parte inferior esquerda, o texto faz um convite ao leitor: "Viva a experiência completa no país anfitrião do Campeonato do Mundo de Futebol em 2014 e dos Jogos Olímpicos e Paralímpicos Rio 2016" (versão em português);

- Na parte inferior direita, a marca Brasil traz a identificação do anunciante, e a palavra, em itálico e com um ponto de exclamação ao final: Sensacional!

Para esta análise, traremos como referenciais teórico-metodológicos, ainda que de maneira não exclusiva, as contribuições de Maingueneau (2004) realizadas à luz de quadros conceituais da Análise do discurso (AD), para os enunciados verbais em seu contexto comunicacional. Este instrumental serve como aporte metodológico, a fim de identificar e tecer observações mais sistemáticas de elementos verbais e icônicos presentes nos anúncios sem, contudo, representar uma rigidez analítica.

Esta opção pela AD pretende confirmar a perspectiva de Coriolano (2005), quando afirma que o turismo tem um discurso próprio, formulado por representantes dos governos, dos empresários e das comunidades, articulado por processos ideológicos e fenômenos linguísticos. A autora explica que, nos materiais que constituem o corpus examinado em sua investigação (textos de jornais, entrevistas, depoimentos de natureza diversa; algumas são peças do planejamento governamental, práticas empresariais e depoimentos de líderes comunitários) o turismo é concebido como uma "opção para o desenvolvimento dos países, estados e municípios e esta superestimação de seu desempenho criou falsas expectativas, pois o turismo, que por si mesmo (...) não tem condições de desenvolver regiões pobres, nem de distribuir a riqueza do país" (Coriolano, 2005, p.53).

$\mathrm{A} A \mathrm{D}$ "é uma disciplina cujos contornos não possuem fronteiras visivelmente demarcadas" (Palacios, 2004, p. 77) visto que seus domínios perpassam os campos da linguística e dialogam com diversos campos das ciências humanas e sociais aplicadas. Maingueneau (2004) considera a AD a partir da compreensão da relação íntima entre a organização textual e sua comunicação. Segundo este teórico, um texto publicitário, por exemplo, não deve ser estudado exclusivamente como um tipo de estrutura textual, uma sequência coerente de signos verbais, ou simplesmente como um dos elementos da estratégia de marketing, mas deve ser considerado uma atividade enunciativa ligada a um gênero de discurso, incluindo o lugar social do qual ele emerge, o canal onde é veiculado (oral, escrito, televisivo...), a extensão da difusão, dentre outros aspectos.

Do mesmo modo, o discurso, segundo Charaudeau (2006), está sempre voltado para outra coisa além das regras de uso da língua, já que resulta da combinação das 
circunstâncias em que se fala ou escreve como, por exemplo, a identidade daquele que fala e daquele a quem este se dirige ou a relação de intencionalidade que os liga e as condições físicas de troca, com a maneira pela qual se fala. Para o autor, é justamente a imbricação das condições extradiscursivas que produz sentido.

Conforme afirmam Knoll e Pires (2010, p. 210), a partir do princípio dialógico bakhtiniano, "não há texto completo ou fechado em si mesmo, pelo contrário, textos e discursos estabelecem uma relação dialógica constitutiva com outros textos e discursos que os antecedem e deles (...) derivam". Assim, considerando a intertextualidade, o texto é definido "como um mosaico de citações que resulta da inscrição de textos anteriores” Kristeva (em Knoll e Pires, 2010, p. 210).

Segundo Maingueneau (2004, p. 95), "toda fala procede de um enunciador encarnado; mesmo quando escrito, um texto é sustentado por uma voz - a de um sujeito situado para além do texto". Deste modo, o autor faz menção à noção de ethos, originária da retórica clássica e retomada como um marco referencial para análise de aspectos discursivos em enunciados midiáticos identificados como publicitários e jornalísticos. De acordo com o autor, o ethos é uma noção discursiva, um processo interativo de influência sobre o outro e, ao mesmo tempo, "uma noção fundamentalmente híbrida (sócio-discursiva), um comportamento socialmente avaliado, que não pode ser apreendido fora de uma situação de comunicação precisa, integrada ela mesma numa determinada conjuntura sócio-histórica". (Maingueneau, 2008, p. 17)

A noção de ethos aplicada à análise do discurso (Maingueneau, 2008) ajuda a compreender, especialmente por tratarmos neste trabalho de gênero publicitário, o que faz os sujeitos aderirem a um discurso, para além de reconhecermos a existência da persuasão, construída a partir de argumentos. Segundo o teórico, o discurso publicitário contemporâneo mantém uma relação privilegiada com o ethos, pois "busca efetivamente persuadir ao associar os produtos que promove a um corpo em movimento, a uma maneira de habitar o mundo" (Maingueneau, 2008, p.19). Além disso, a publicidade, segundo o mesmo autor, apoia-se em estereótipos validados, para encarnar o que prescreve.

Orientando-se a partir dos pressupostos de Maingueneau a respeito dos estereótipos, Heine (2009, p. 66) explica que os estereótipos, gestados socialmente, influenciam tanto a construção do ethos pré-discursivo (primeira imagem que se faz do enunciador) quanto do ethos discursivo (circunscrito à enunciação, sendo a imagem que o enunciador cria de si discursivamente). A autora defende que "a estereotipagem leva o coenunciador a observar a realidade, tomando como base uma dada representação social cristalizada". Heine (2009) ressalta ainda que os estereótipos podem ser confirmados pelo que Maingueneau (2004) chama de 'cena validada', ou seja, a que está instalada na memória coletiva e é aceita como padrão.

O ethos é composto por uma instância subjetiva que desempenha o papel de fiador do que é dito através do discurso. A este fiador, cuja construção é feita a partir de indícios textuais de diversas ordens, são atribuídos um caráter e uma corporalidade. 0 caráter corresponderia a uma gama de traços psicológicos e a corporalidade seria a compleição corporal, os dois construídos a partir de uma diversidade de representações sociais e estereótipos culturais que circulam em diversos domínios, tais como literatura, fotos, cinema, publicidade, dentre outros (Maingueneau, 2004). 
Assim, no decorrer da análise do corpus a seguir, buscamos identificar seus elementos verbais e não verbais, a identificação dos personagens fiadores na cena e a formação do ethos discursivo. E, no conjunto dos anúncios, objetivamos perceber o interdiscurso e, especialmente, a relação com as identidades brasileiras.

A Figura 2 é do anúncio que retrata o cenário do carnaval na cidade de Recife, no estado de Pernambuco.

Figura 2 - Anúncio que retrata Carnaval de Recife-PE

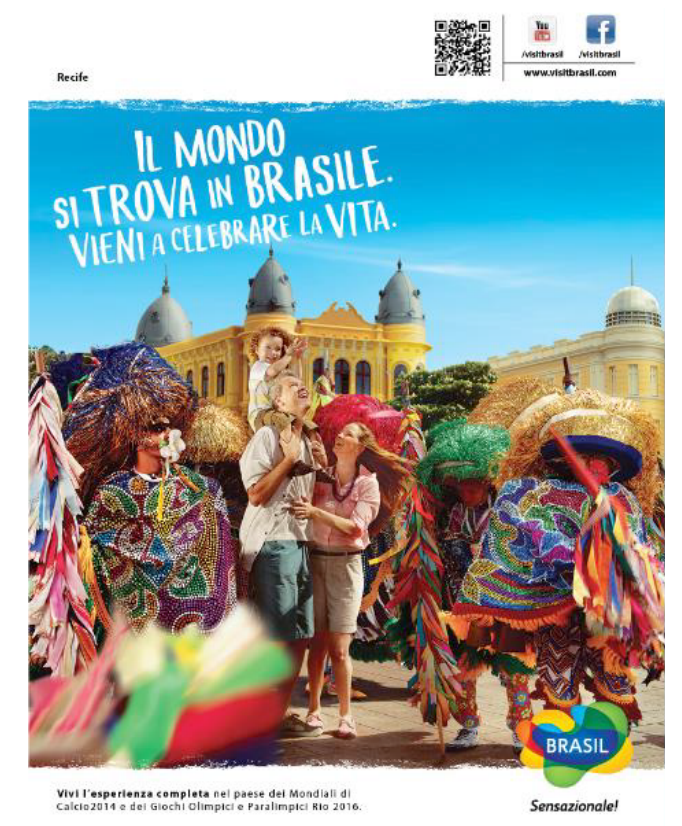

Fonte - Instituto Brasileiro de Turismo (2014)

Este anúncio traz como cenário uma celebração cultural típica de Pernambuco, o Maracatu, no centro histórico da capital do Estado, a cidade de Recife. Essa construção discursiva remete à imagem de um local cuja cultura é dinâmica e harmoniosa, visto que uma expressão popular e festiva ocorre em meio a edificações históricas revitalizadas. Há uma associação entre o cenário histórico e a celebração popular, reunidos em uma só imagem. 0 cenário histórico, por meio de seus edifícios, e a manifestação popular, por meio dos integrantes do grupo que brincam o Maracatu, reúnem-se em uma só imagem e são igualmente exaltados e valorizados.

Para o reconhecimento do Maracatu, enquanto expressão cultural brasileira, tipicamente pernambucana, há a necessidade de uma competência enciclopédica por parte do coenunciador, ou seja, um conhecimento cultural prévio. Entretanto, embora o carnaval do Recife seja uma das maiores festas populares do país, é pouco provável que a maioria dos coenunciadores, formada por pessoas que compreendem o idioma italiano, reconheça esta expressão cultural. Contudo, mesmo sem o reconhecimento prévio do Maracatu, o universo de sentido construído é o de uma festa popular, colorida, que envolve dança e música e um certo exotismo, que pode ser visto nas roupas brilhantes e volumosas, mesmo em meio ao calor de um dia ensolarado.

A presença central no anúncio do grupo familiar, com fenótipos e vestimentas bem diferentes das pessoas à sua volta, indica que os mesmos são turistas e, portanto, os fiadores do discurso. Os personagens possibilitam a identificação e a adesão 
do coenunciador ao anúncio - o leitor pode se identificar com esses personagens e querer, também, envolver-se e viver aquela experiência cultural alegre, festiva e exótica em um país distante, situado na América do Sul que, além disso, está sediando a Copa do Mundo e as Olimpíadas, como atrativos de caráter supranacional.

O jovem núcleo familiar, composto por um casal e seu filho, harmoniosamente integrado com o ambiente à sua volta, representa também um posicionamento do anunciante em relação a seu leitor. A cidade do Recife (aqui representando o Brasil) encarna o ethos do exotismo cultural, estereótipo normalmente relacionado ao país, para atrair seu público alvo. Contudo, a escolha por um núcleo familiar como fiador deste anúncio indica que, apesar do exotismo, este destino turístico está preparado, oferece segurança e é indicado para diferentes perfis de público e faixas etárias, incluindo crianças.

É possível perceber no anúncio que, como bem aponta Conceição (1998, p. 84), a promoção turística vê-se obrigada a indicar o que denomina como ritualização das práticas turísticas, ou seja, "a materialização das suas ofertas sob a forma de um produto passível de apropriação/consumo". Ao mesmo tempo, conforme a autora aponta, a publicidade turística propõe-se a realizar uma antecipação da experiência a ser vivida pelo consumidor, como uma estratégia fundamental para a sedução de potenciais turistas. Quando os personagens, no caso deste anúncio, estão imersos na manifestação cultural, a construção discursiva pretende antecipar a experiência a ser vivida (não apenas contemplada) naquele destino turístico: a cidade de Recife, capital do estado de Pernambuco, situada na região nordeste do país.

A Figura 3 apresenta cenário em que o destaque é uma praia na cidade do Rio de Janeiro.

Figura 3 - Anúncio de praia da cidade do Rio de Janeiro-RJ

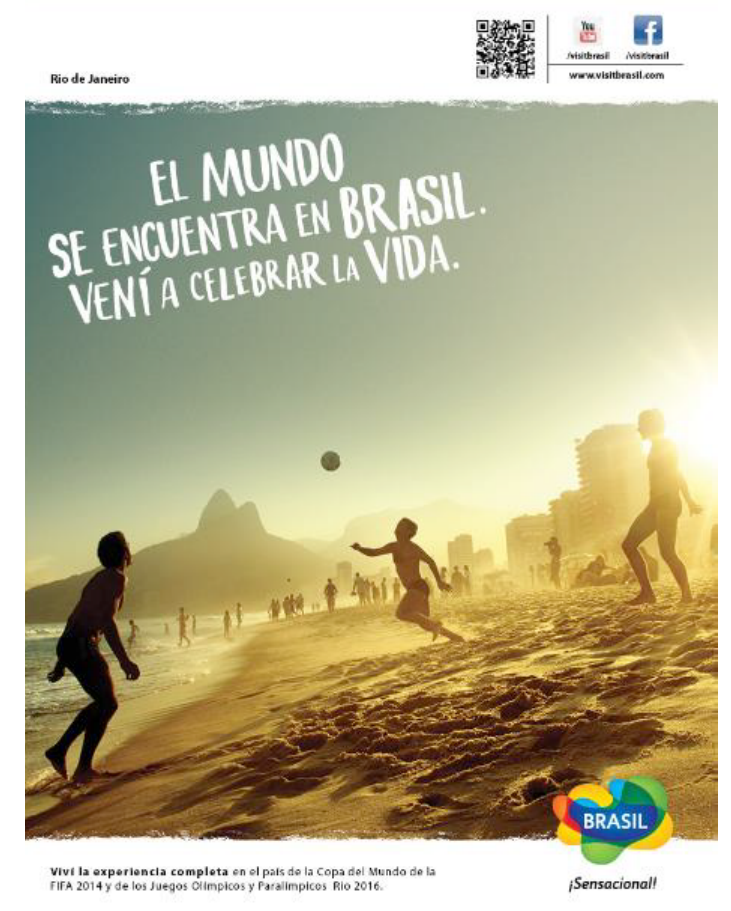

Fonte - Instituto Brasileiro de Turismo (2014) 
Este anúncio, repleto de significantes, retrata uma bela praia na cidade do Rio de Janeiro. A cena de enunciação construída demonstra que, no destino mais conhecido internacionalmente do Brasil, as pessoas aproveitam o dia, especificamente a praia, para praticar futebol, esporte mais apreciado pelos brasileiros. Há a correlação da prática esportiva com a realização dos eventos esportivos internacionais realizados no país em 2014 e em 2016.

Neste anúncio, o universo de sentido a que remete o discurso inclui valores como a celebração e a realização de práticas esportivas. Ao coenunciador, através dos fiadores do discurso (os personagens em primeiro plano que jogam bola) é prometida a experiência de apreciar o futebol não apenas através dos confrontos nos estádios de futebol: o visitante pode viver a experiência completa e jogar bola em um fim de tarde de uma bela praia carioca. 0 ethos presente na imagem, para além de convidar o potencial turista a praticar o futebol improvisado na areia da praia, também põe em relevo um traço cultural bastante evocado em relação aos cariocas: descontração e desfrute do tempo em meio ao ar livre.

Embora em outros anúncios da campanha sejam evidenciadas expressões culturais menos conhecidas internacionalmente, no anúncio referente à cidade do Rio de Janeiro são reforçados dois símbolos bastante massificados na mídia internacional e na própria trajetória discursiva da Embratur a respeito do Brasil: o espaço democrático da areia das praias cariocas e a prática improvisada e amistosa do futebol, popularmente conhecida por meio de várias acepções, dentre elas, a difundida "pelada" e a denominação coloquial baiana "baba".

Gastaldo (2005, p. 116) considera que, ainda que a mítica do país do futebol seja fruto de um processo histórico e social que se alastra há mais de cinquenta anos. Para o autor, o futebol é, atualmente, um dos "principais emblemas da identidade brasileira, juntamente com o samba e as chamadas religiões afro-brasileiras", para além de ser um fato social de extrema importância simbólica no Brasil que se encontra indissociavelmente ligado à sua midiatização.

Deste modo, o anúncio da cidade do Rio de Janeiro dialoga com essa importância simbólica do futebol, valendo-se desse estereótipo bastante disseminado em relação à imagem do país, sobretudo porque a estratégia de veiculação desta campanha é divulgar o país no período que antecede a realização da Copa do Mundo.

Além do futebol, a peça também remete ao turismo de sol e praia, realça as belezas naturais da cidade do Rio de Janeiro e, sobretudo, valoriza a ideia de aproveitar o dia e "celebrar a vida" em um cenário que é ocupado por cariocas, brasileiros e turistas.

O anúncio da Figura 4 tem como cenário a cidade de Salvador, capital da Bahia.

Este anúncio destaca a presença de uma importante expressão cultural brasileira - a capoeira, considerada em dezembro de 2014 pela Organização das Nações Unidas para a Educação, a Ciência e a Cultura - UNESCO - como Patrimônio Imaterial da Humanidade. De acordo com informações do Ministério da Cultura,

(...) no século XVII, em pleno período escravista, a capoeira desenvolveu-se como forma de sociabilidade e solidariedade entre os africanos escravizados, estratégia para lidarem com o controle e a violência. Hoje, é um dos maiores símbolos da identidade brasileira e está presente em todo território nacional, além de ter praticantes em mais de 160 países, em todos os continentes (Ministério da Cultura, 2014) 
Figura 4 - Anúncio que retrata a cidade de Salvador-BA

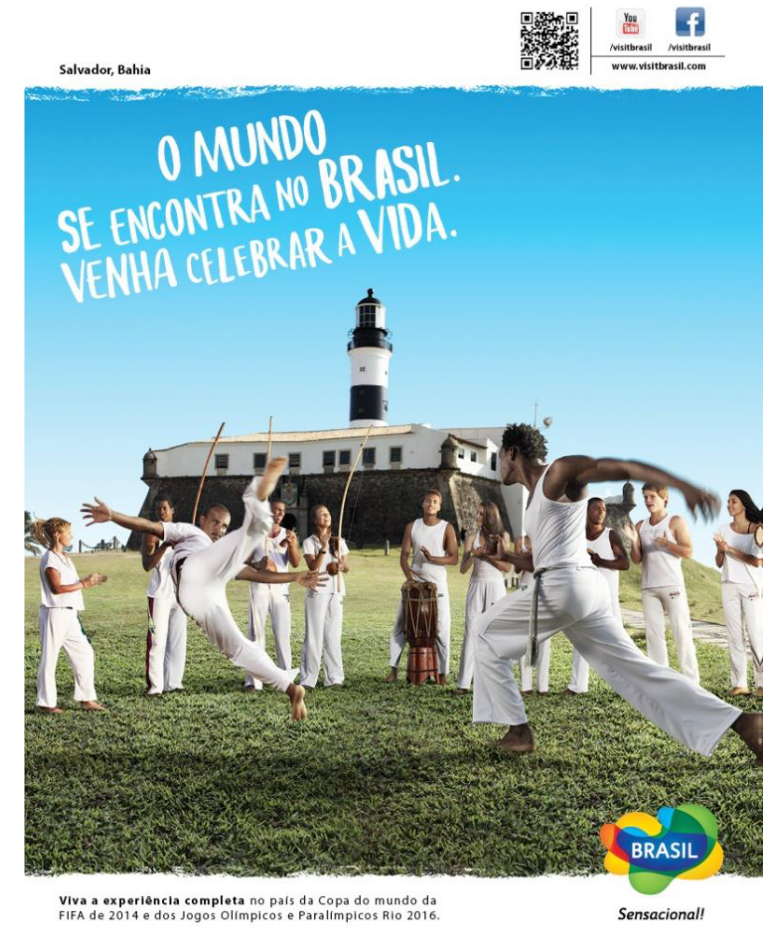

Fonte - Instituto Brasileiro de Turismo (2014)

Há, como vimos, uma forte associação, segundo o próprio Ministério da Cultura, da capoeira com a identidade brasileira e seu reconhecimento mundial como tal. A Embratur, portanto, apropria-se desta 'cena validada' (Maingueneau, 2004) que reconhece ser a capoeira uma forte expressão da cultura brasileira para atrair a adesão de seu público alvo.

Contudo, a inserção da capoeira neste anúncio indica a possibilidade de ser praticada e não apenas contemplada pelos turistas. 0 coenunciador poderá aderir ao universo de sentido construído pelo anúncio, novamente validada pelos fiadores da cena (o grupo heterogêneo de personagens praticantes da capoeira), através do ethos que inclui valores como hospitalidade, acolhimento e valorização do outro e da diversidade cultural.

Contudo, a realidade reproduzida no anúncio difere um tanto daquela que costumamos ver em rodas de capoeira realizadas no Centro Histórico da cidade de Salvador, especialmente "jogadas" em frente ao tradicional Mercado Modelo, onde grupos de capoeira compostos majoritariamente por jovens negros baianos fazem acrobacias e, à sua volta, turistas permanecem assistindo ao "espetáculo" e fotografando-o. Na construção cênica deste anúncio não há observadores externos à roda de capoeira. No espaço cênico do anúncio, todos estão reunidos, fazendo parte da roda, praticando, tocando e cantando, juntos, os cânticos tradicionalmente relacionados com a prática da capoeira.

Cabe destacar a escolha da capoeira em detrimento de outros atrativos que, tradicionalmente, compõem os anúncios publicitários alusivos à cidade de Salvador, a exemplo do conjunto arquitetônico do Pelourinho e das belezas naturais da cidade. A escolha da capoeira, praticada junto a um importante símbolo da cidade de Salvador - o Farol da Barra, indica a valorização de uma manifestação 
cultural dinâmica e que remete à herança dos povos africanos trazidos ao Brasil durante a colonização do país.

Ademais, o conjunto de significantes composto pela edificação histórica do Farol da Barra, o grupo heterogêneo praticando capoeira, o céu azul e o gramado bem preservado sintetizam a promessa de experiência a ser vivida no país, anunciada pelo enunciador, neste e nos outros anúncios da campanha: um país que preserva sua cultura e sua história, que possui um clima agradável e ricas expressões culturais e que, sobretudo, abriga a diversidade étnica.

0 anúncio da Figura 5 retrata a imagem de um restaurante, na cidade de São Paulo.

Figura 5 - Anúncio que retrata restaurante de São Paulo-SP

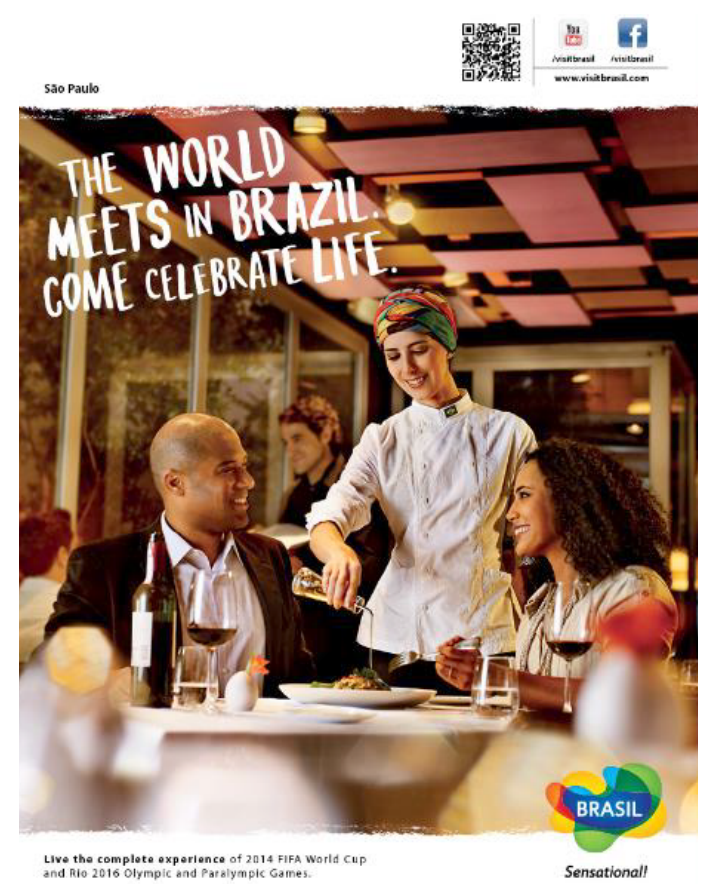

Fonte - Instituto Brasileiro de Turismo (2014)

O anúncio que tem por cenário a cidade de São Paulo traz elementos importantes para mostrar ao coenunciador, caso tenha interesse em visitar o país, fatos que talvez desconheça tais como: a possibilidade de um serviço de excelência em gastronomia (a própria chef faz o atendimento aos clientes), o toque de regionalidade importante para demonstrar a valorização da cultura local (percebido através da utilização de lenço estampado e amarrado como turbante) e, especialmente, o tratamento igualitário, que independe da origem racial ou gênero da pessoa.

0 coenunciador que aderir ao universo de sentido construído e se identificar com os fiadores do discurso - os três personagens centrais do anúncio - poderá viver a experiência de ser atendido pelo próprio chef de cozinha em restaurantes da cidade de São Paulo, metrópole que figura entre as grandes cidades do mundo e se destaca pela oferta ampla de opções gastronômicas. Estas características são fundamentais para receber um grande evento internacional - como a Copa do Mundo e os Jogos Olímpicos - e evidenciam que o país oferece um serviço especializado e requintado, no setor de alimentação, sem perder as características da cultura local, como a simpatia e a hospitalidade. Pretendem também mostrar que 
o Brasil é um país apto a receber turistas do mundo inteiro, independentemente de suas características e idiossincrasias, uma vez que reúne traços históricos marcados por qualidades, tais como saber lidar com as diferenças e tolerância em relação à diversidade étnica.

Sabemos, contudo, que o mito da igualdade racial, baseada em uma suposta mistura de raças, suprime diversos fatos históricos ligados ao passado escravocrata do país e seus reflexos na sociedade brasileira contemporânea. No entanto, o fato desta peça apresentar uma pessoa branca servindo um casal de negros é importante, simbolicamente, para sinalizar o processo, ainda que lento e não isento de conflitos e retrocessos, de mudanças sociais em curso, reivindicadas pelos movimentos populares que clamam pela correção das desigualdades e erradicação das injustiças sociais praticadas há mais de 500 anos, em relação aos afrodescendentes. As expressões destes clamores podem ser observadas nos amplos domínios da cultura midiática e no contexto sócio histórico e cultural brasileiro.

Sobretudo em uma peça publicitária situada em um contexto de realização de Copa do Mundo de Futebol, esporte em que, segundo Gastaldo (2013, p. 88), há uma ritualização das relações raciais, onde "negros jogam e brancos torcem", o discurso publicitário produzido por um órgão oficial de turismo representa uma mudança, mesmo que tímida, na lógica racial hegemônica e mitos que a acompanham.

Após a breve leitura interpretativa dos anúncios, realizada por meio de um exercício constante de aproximação e distanciamento em relação às pistas oferecidas pelos textos e imagens descritas até aqui, observamos que em todas as peças da campanha é valorizado o "consumo da experiência" (Pereira, Siciliano, \& Rocha, 2015, p. 10), ou seja, a realização da prática turística vai além da contemplação de monumentos, manifestações culturais ou belos cenários naturais. 0 foco na experiência permite, ou ao mesmo promete, ao turista vivenciar e inserir-se de forma mais próxima na realidade local. Nesta campanha, os personagens (brasileiros ou turistas - muitas vezes não é possível identificar) aparecem interagindo, celebrando, em harmonia com o ambiente. Todos revelam ações humanas, ligadas ao lazer. Ou seja, a promessa que identificamos na estrutura discursiva é a de que o turista que vier ao Brasil terá a oportunidade de, mais do que contemplar uma bela cidade ou assistir a uma manifestação cultural, poder vivenciá-las junto com brasileiros e com os demais turistas de outras nacionalidades.

Contudo, constatamos que na cobertura idílica da realidade brasileira pela propaganda turística, os problemas sociais do país são ocultados. Como bem aponta Paganotti (2011), "mitos fundadores do Brasil e diversos estereótipos sobre a imagem do país como Paraíso Terrestre são repetidos ou readaptados” (p.59), as cenas de violência e miséria encobertas, e a impressão que se deixa transparecer é que os turistas podem "viver numa redoma, distantes dos riscos e dos problemas brasileiros" (p.60).

0 ethos discursivo presente no conjunto dos anúncios analisados remete sempre à hospitalidade, valorização da diversidade cultural e étnica, à interação entre as pessoas e à celebração cotidiana. 0 país mostrado nos anúncios é um lugar que reúne belezas naturais e diversidade cultural de modo harmonioso. Não há espaço nas escolhas enunciativas para qualquer menção ou indicação de que neste mesmo país existem agravados problemas sociais, decorrentes da pobreza, violência e conflitos raciais que, inclusive, podem colocar em risco a própria segurança e integridade física dos visitantes. 


\section{CONSIDERAÇÕES FINAIS}

Após análise do conjunto de anúncios, podemos concluir que, ainda que seja representada uma maior diversidade de atrativos turísticos em relação a campanhas anteriores promovidas pela Embratur, notamos uma visão unificada e homogeneizante sobre os brasileiros, como se todos compartilhassem uma identidade única, associada especialmente à alegria e à hospitalidade, como traço cultural inerente à população brasileira. Ao mesmo tempo, observamos que estratégias discursivas da referida campanha estão, majoritariamente, voltadas para a alusão e ao apelo para o desfrute, à fruição, da experiência turística e também para o encontro pacífico e festivo entre diferentes culturas.

O discurso turístico promovido pela Embratur, órgão cuja responsabilidade é atrair turistas estrangeiros para o país, é o de retratar um país cujo principal diferencial são as expressões de modos de viver da população brasileira. Por meio da utilização de estereótipos socialmente validados acerca do país (como a capoeira e o futebol) e sua conjunção com aspectos menos difundidos a respeito da imagem turística do Brasil (a exemplo do maracatu), a Embratur apresenta um país com uma extensa diversidade cultural. Ademais, é possível perceber uma representação idealizada e estereotipada sobre a realidade brasileira, sobretudo no que tange aos aspectos sociais, étnicos raciais, econômicos e ambientais.

Ao mesmo tempo, a promessa do encontro entre diferentes culturas permeia o universo de sentido construído no conjunto dos anúncios que integram a campanha. Orientada em parte pelo slogan "O mundo se encontra no Brasil", a campanha faz referência aos megaeventos esportivos realizados no país e, ao mesmo tempo, à diversidade cultural e étnica. Uma suposta democracia étnico-racial também é evidenciada - o que, se por um lado oculta o racismo ainda presente no nosso país, por outro, representa um avanço significativo do ponto de vista simbólico, já que mostra pessoas afrodescendentes positivamente inseridas no mercado de consumo turístico (a exemplo do casal presente no anúncio da cidade de São Paulo).

Entretanto, apesar de ser um país com dimensões territoriais continentais e reunir uma grande diversidade de atrativos turísticos naturais e culturais, o Brasil ainda está muito aquém de seu potencial de atratividade turística. Dos mais de 1,4 bilhão de turistas internacionais que circulam em todo o planeta, representando 10\% do PIB mundial (OMT, 2018), apenas 6,3 milhões chegaram ao Brasil no ano seguinte à realização da Copa do Mundo (2015).

Tabela 1 - Chegadas de turistas ao Brasil 2013 a 2018

\begin{tabular}{|l|c|c|c|c|c|c|}
\hline & 2013 & 2014 & 2015 & 2016 & 2017 & 2018 \\
\hline $\begin{array}{l}\text { Número } \\
\text { Total de } \\
\text { Turistas }\end{array}$ & 5.813 .342 & 6.429 .852 & 6.305 .838 & 6.578 .074 & 6.588 .770 & 6.621 .376 \\
\hline
\end{tabular}

Fonte - Anuário Estatístico de Turismo (2018)

Existem entraves relevantes em relação à atração de mais turistas internacionais para o Brasil no que diz respeito a aspectos operacionais, como o número de voos para o país e a distância em relação aos principais países emissores de turistas, localizados na Europa e América do Norte, o que repercute em viagens mais dispendiosas comparadas a outros destinos. Contudo, 
é possível concluir que aspectos negativos relacionados à imagem do país no exterior, sobretudo ligados à pobreza, violência, tráfico de drogas e turismo sexual influenciam negativamente a atratividade do Brasil, em relação aos seus principais concorrentes.

Foram muitas as ações estratégicas de construção de imagem realizadas pela Embratur e Ministério do Turismo, antes, durante e após a realização da Copa do Mundo, no sentido de apresentar a diversidade cultural brasileira e as demais características positivas do país. Contudo, e apesar evento da FIFA ter transcorrido de forma harmoniosa na convivência entre os povos de diversas nacionalidades presentes, após a realização do megaevento, foi veiculado um painel no Salão Internacional do Automóvel, em Frankfurt, Alemanha, em setembro de 2015, que consta da Figura 6.

Figura 6 - Painel exposto no Salão Internacional do Automóvel de Frankfurt

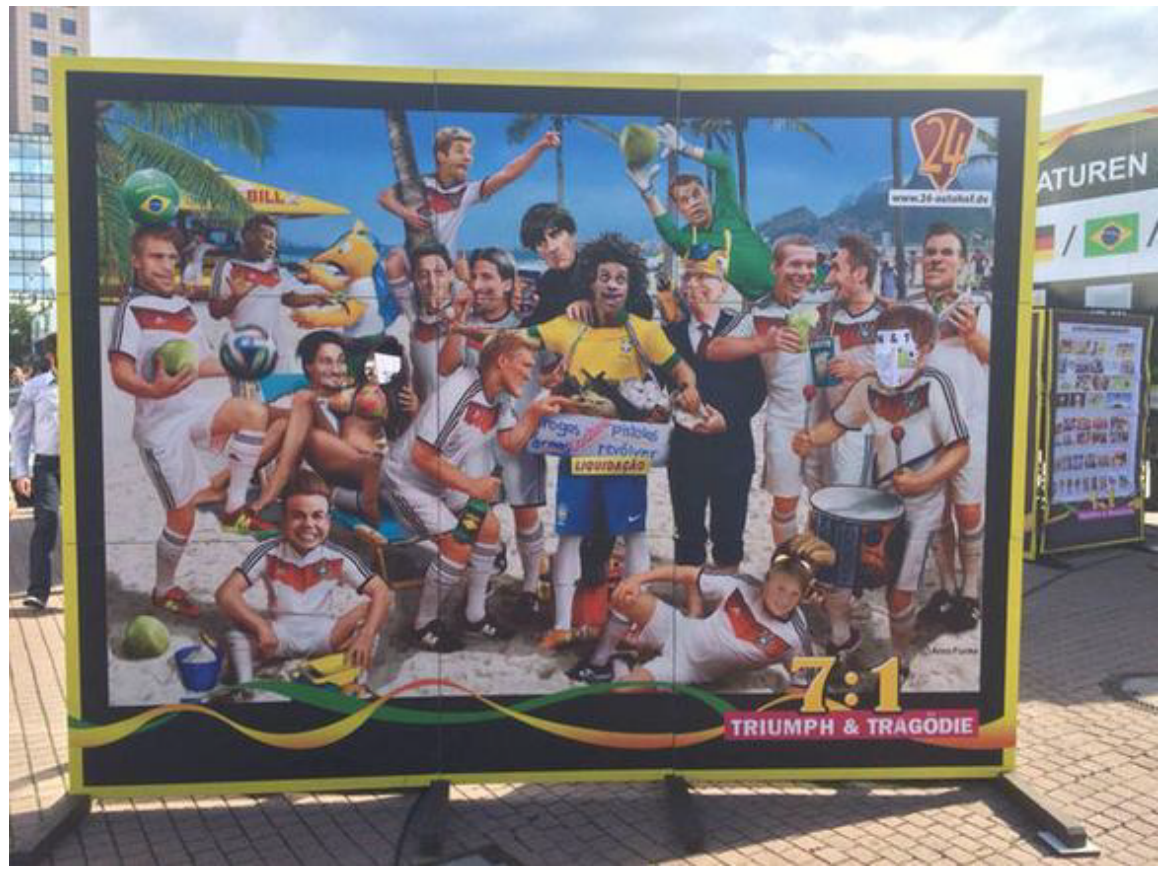

Fonte - Lancepress Jovempan (2015)

0 referido painel, de autoria do artista alemão Arno Funke, traz uma charge com a equipe da seleção alemã, que foi a campeã da Copa do Mundo realizada no Brasil, em um cenário de uma praia. A legenda "7:1 - Triumph \& Tragodie" faz referência à vitória com o placar de 7x1 da Alemanha sobre a seleção brasileira. Entretanto, chama a atenção na imagem os diversos símbolos negativos relacionados ao país: o "fuleco", mascote oficial do evento da Fifa, aparece assaltando um jogador alemão; uma mulher, de biquíni, está sentada no colo de outro jogador; ao centro da imagem, o jogador da seleção brasileira, negro, com um tabuleiro vendendo "drogas", "cocaína" e "armas", tudo em "liquidação", isso ao lado de um homem engravatado, com uma arara no ombro, provavelmente a representação de um político. Há também um jogador com uma garrafa de bebida em mãos, outro com uma caipirinha, enquanto seu colega toca um tambor. A expressão facial dos jogadores alemães é de alegria; já o jogador brasileiro está com os olhos arregalados, com uma feição que aparenta alucinação. 
Portanto, o painel reúne diversos estereótipos negativos associados ao país, como a exploração sexual feminina, a violência urbana, o tráfico e o uso de entorpecentes, ao lado de outros símbolos culturais, como a tradicional bebida caipirinha e o tambor. A celebração retratada por um chargista alemão revela como a imagem do Brasil, mesmo após a realização da Copa do Mundo ter decorrido em segurança e sem grandes percalços, permanece extremamente estereotipada e associada a aspectos negativos muito significativos, pelo menos do ponto de vista de uma instituição alemã responsável pela realização do Salão Internacional do automóvel de Frankfurt, na Alemanha (Internationale Automobil Ausstellung).

O governo brasileiro fez um grande investimento político e financeiro ao sediar dois principais eventos esportivos mundiais e apostar nos legados de infraestrutura, de qualificação e, sobretudo, de imagem a serem herdados após sua realização. A reunião das incontáveis equipes da imprensa internacional no país para a cobertura dos jogos levaria a uma oportunidade única em termos de exposição midiática. A Copa do Mundo e as Olimpíadas são muito mais do que eventos esportivos; são, sobretudo, eventos midiáticos. E justamente por operar segundo práticas, lógicas e esquemas de codificação próprios da cultura da mídia (Fausto Neto, 2008) é impossível controlar o que está sendo veiculado e como o Brasil é exibido internacionalmente. País do futebol, de povo alegre e festeiro e rico culturalmente ou lugar onde ainda prevalecem o sexo fácil, o tráfico de drogas, a pobreza, a violência e a corrupção? Certamente prevalece na própria constituição desses eventos e na cobertura midiática dos mesmos a "lógica da mídia" a que Hjarvard (2013) se refere: os modus operandi institucionais, estéticos e tecnológicos adotados pela mídia, incluindo a forma como os recursos materiais e simbólicos são distribuídos.

O discurso turístico institucional brasileiro, nas peças analisadas, transita, ideologicamente, em uma faixa de compreensão da realidade brasileira fundamentada na reafirmação de traços identitários brasileiros de viés preservacionista e tradicional. Traços estes que parecem exprimir um Brasil modernista, desenvolvimentista, historicamente vocacionado para o ideal de um país que cresce pacífica, alegre e despreocupadamente, em direção a uma sociedade na qual todos celebram a vida, independentemente de condições sócio culturais marcadas por distinções étnicas, de gênero, educacionais, econômicas, religiosas, dentre outras.

Concluímos, portanto, que permanece o paradoxo do discurso turístico institucional do Brasil: ainda que reforce o imaginário de um país associado às suas vastas riquezas naturais e de um povo pacífico, acolhedor, alegre e culturalmente diversificado é impossível controlar a agenda midiática, muito maior do que aquela circunscrita à publicidade institucional, e, sobretudo, os inúmeros acontecimentos políticos, sociais, ambientais e econômicos que ocorrem no país. Ou seja: o discurso de promoção turística parece não convencer ou não ser suficiente para fomentar o turismo e também aumentar o número de visitantes internacionais que chegam ao país.

\section{REFERÊNCIAS}

Bauman, Z. (2005). Identidade: entrevista a Benedetto Vecchi. Rio de Janeiro: Zahar.

Baudrillard, J. (1981). Simulacros e simulação. Lisboa: Antropos. 
Canclini, N. G. (2008). Consumidores e cidadãos. 7. ed. Rio de Janeiro: Editora UFRJ.

Charaudeau, P. (2006). Discurso das mídias. São Paulo: Contexto.

Conceição, C. P. (1998). Promoção turística e (re)construção social da realidade. Sociologia: problemas e Práticas, Lisboa, n. 28, p. 67-89, dez. 1998.

Coriolano, L. N. M. T. (2005) Epistemologia da análise do discurso no turismo. Caderno Virtual de Turismo. Vol. 5, $\mathrm{N}^{\circ} 2$.

Fausto Neto, A. (2008). Fragmentos de uma «analítica» da midiatização. Matrizes, 1(2), 89-105.

Freitas, N. K (2013). Representação, simulação, simulacro e imagem na sociedade contemporânea. In: Polêmica. 12(2), 334-340.

Garcia, L. F. D., Júnior, I. R., \& Sant'Anna, A. (2009). Propaganda: teoria, técnica e prática. São Paulo: Cengage Learning.

Gastal, S. D; Sales, F de L. (2012). Identidades sob o turismo: A italianidade no sul do Brasil. Revista Iberoamericana de Turismo - RITUR, Penedo, vol. 2, n.1, p. 22-35. Recuperado em 27 jan. 2019 de: http://www.seer.ufal.br/index.php/ritur.

Gastaldo, E. (2013). Publicidade e sociedade: uma perspectiva antropológica. Porto Alegre: Sulina.

Gastaldo, E. (2005) Uma arquibancada eletrônica: reflexões sobre futebol, mídia e sociabilidade no Brasil. CAMPOS Revista de Antropologia Social. v. 6. Recuperado em 27 jan. 2019 de: http://revistas.ufpr.br/campos/article/view/4512.

Hall, S. (1997) A identidade cultural na pós-modernidade. Rio de Janeiro: DP\&A Ed.

Hjarvard, S. (2013) A midiatização da cultura e da sociedade. São Leopoldo: Ed. UNISINOS.

Heine, P. (2009) Navegando na enunciação digital: processos de construção do ethos em blogs de pré-universitários e universitários. Tese (doutorado). Instituto de Letras, Universidade Federal da Bahia. Salvador. 27 jan. 2019.

Instituto Brasileiro de Turismo (2012a). Prestação de Contas Ordinária Anual. Relatório de Gestão do Exercício de 2011. Brasília, DF. Recuperado em 27 jan. 2019 de: http://www.embratur.gov.br/lai_embratur_secom/export/sites/lai/galerias/download/ RelatorioGestaoEmbratur2011.pdf.

Instituto Brasileiro de Turismo (2012b). Encarte da campanha publicitária "O mundo se encontra no Brasil. Venha celebrar a vida". Brasília, DF.

Instituto Brasileiro de Turismo (2014). Publicação eletrônica [mensagem pessoal]. Mensagem recebida por < paty_tur@yahoo.com.br> em 28 abr. 2014.

Knoll, G. F; Pires, V. L. (2010). Intertextualidade e propaganda: análise de processos intertextuais em anúncios impressos. In: Anais do SITED Seminário Internacional de Texto, Enunciação e Discurso. Porto Alegre, RS. Recuperado em 27 jan. 2019 de: http://editora. pucrs.br/anais/sited/arquivos/GrazielaFrainerKnolleVeraLuciaPires.pdf.

Lamo de Espinosa, E. (1993). La mirada del otro. La imagen de España en el extranjero. Revista de Economía, 722, 11-26.

Lancepress Jovempan (2015) recuperado em 27 jan. 2019 de: http://jovempan.uol.com. $\mathrm{br} /$ esportes/futebol/selecao-brasileira/com-drogas-armas-e-7-1-salao-de-automovelalemao-faz-satira-com-o-brasil.html.

Maingueneau, D. (2008). A propósito do Ethos. In: Motta, A. R.; Salgado, L. (orgs.). Ethos Discursivo. São Paulo: Contexto.

Maingueneau, D. (2004). Análise de textos de comunicação. 3. ed. São Paulo: Cortez.

Ministério da Cultura (2014). Plano Nacional de Cultura. Recuperado em 27 jan. 2019 de: http://pnc.cultura.gov.br/tag/roda-de-capoeira/. 
Ministério do Turismo (2018) Anuário Estatístico de Turismo - 2017 - Ano base 2016. Recuperado em 27 jan. 2019 de: http://www.dadosefatos.turismo.gov.br/dadosefatos/ home.html.

OMT (2018) Country profile - outbound tourism. Recuperado em 20 jan. 2019 de https://www.unwto.org/country-profile-outbound-tourism

Palacios, A. da R. J. (2004) As marcas na pele, as marcas no texto: sentidos de tempo, juventude e saúde na publicidade de cosméticos em revistas femininas durante a década de 90.2004. Tese (Doutorado). Faculdade de Comunicação, Universidade Federal da Bahia, Salvador, 2004. Recuperado em 20 jan. 2019 de: https://repositorio.ufba.br/ri/handle/ri/11292.

Paganotti, I. (2011). Imagens do Brasil Turístico nas páginas do New York Times. Pensamento \& Realidade, 24(2). Recuperado em 27 jan. 2019 de: http://revistas.pucsp.br/ pensamentorealidade/article/view/7083.

Pazos-Justo, C. (2017). Turismo, imagem e comunidade: reflexões a partir do caso de Santiago de Compostela. In F. G. Bouza \& P. Dono López (Eds.), Galegos no Minho: 20 anos do Centro de Estudos Galegos (pp. 79-92). Húmus.

Pereira, C. da S., Siciliano, T., \& Rocha, E. (2015). Consumo de experiência" e "experiência de consumo": Uma discussão conceitual. Logos, 22(2), 6-17. Recuperado em 27 jan. 2019 de: http://doi.org/10.12957/LOGOS.2015.19523.

Silva, T. T. da. (2012). A produção social da identidade e da diferença. In: Silva, T. T. (Org.). Identidade e diferença: a perspectiva dos Estudos Culturais. 12 ed. Petrópolis, RJ: Vozes.

Tomazzoni, E. L. (2006). Análise do discurso turístico da Serra Gaúcha. In: Em Questão, vol. 12, n. 2, jul-dez, 2006, pp. 339-365. Recuperado em 27 jan. 2019 de: https://seer.ufrgs. br/EmQuestao/article/view/41.

Vieira, L. (2009). Morrer pela pátria? Notas sobre identidade nacional e globalização. In: Vieira, L. (org.) Identidade e globalização: impasses e perspectivas da identidade e a diversidade cultural. Rio de Janeiro: Record, 2009.

Voisin, J. (2004). Comunicação turística, memória, identidade: uma proposta de abordagem e dois casos (Ilhéus-Bahia e La Rochelle-França). In: Revista Espaço Acadêmico, n. 37, junho de 2004. Recuperado em 27 jan. 2019 de: http://www.espacoacademico.com. br/037/37 evoisin.htm.

White, L. (2017). Commercial nationalism and tourism: selling the national story. Bristol: Channel View Publications.

Woodward, K. (2012). Identidade e diferença: uma introdução teórica e conceitual. In: Silva, T. T. (org.). Identidade e diferença: a perspectiva dos estudos culturais. 12 ed. Petrópolis, RJ: Vozes.

Recebido em: 22/04/2018

Aprovado em: 11/11/2018

\section{CONTRIBUIÇÕES}

Patricia de Souza Figueredo Lima: definição do problema de pesquisa e objetivos, desenvolvimento da proposição teórica, realização da revisão bibliográfica e fundamentação teórica, escolha dos procedimentos metodológicos, coleta de dados, análise de dados, elaboração de tabelas, gráficos e figuras, redação do manuscrito e adequação do manuscrito às normas da RTA.

Annamaria da Rocha Jatobá Palacios: desenvolvimento da proposição teórica, realização da revisão bibliográfica e fundamentação teórica, escolha dos procedimentos metodológicos e Revisão crítica do manuscrito. 